\title{
LANGUAGE ACQUISITION OF ENGLISH VOCABULARY ON 5 YEARS OLD CHILD THROUGH SOCIAL MEDIA YOUTUBE
}

\author{
Hernalia Citra Dewi \\ Universitas Indraprasta PGRI \\ *) Correspondences author: Jl. Nangka Raya No. 58 C, Tanjung Barat, Jagakarsa, Jakarta Selatan, DKI Jakarta, 12530, Indonesia; \\ e-mail: hernaliacitradewi18@gmail.com
}

\begin{abstract}
Language acquisition cannot just be acquired from birth. There is a process and stages in acquiring a language. Language is obtained because of the continuous practice factor. It is possible for someone who already has a mother tongue to have a second language (B2) which is used as a communication tool alongside the first language. Acquisition of a second language can be obtained through the influence of the environment or activities carried out continuously. This study will describe how the effect of viewing on social media YouTube affects the acquisition of a second language for a five years old girl. This research uses qualitative methods with descriptive explanations. The results of this study found that the subject's second language proficiency in English was evident from his understanding of the films and videos she had watched repeatedly. His mastery of a second language can also be seen in the ability of the subject to mention the objects around her, the names of fruits and animals, and to be able to make simple sentences in English.
\end{abstract}

Keywords: Language acquisition, second language, YouTube.

\begin{abstract}
Article History: Received: 25/05/2021; Revised: 31/05/2021; Accepted: 15/06/2021; Published: 30/06/2021.
How to Cite (MLA $7^{\text {th }}$ ): Dewi, Hernalia Citra. "Language Acquisition of English Vocabulary on 5 Years Old Child Through Social Media YouTube." Hortatori: Jurnal Pendidikan Bahasa dan Sastra Indonesia 5.1 (2021): 38-44. Print/Online. Copyrights Holder: Hernalia Citra Dewi. First Publication: Hortatori: Jurnal Pendidikan Bahasa dan Sastra Indonesia (2017).
\end{abstract}

This work is licensed under a Creative Commons Attribution-ShareAlike 4.0 International License.

\section{Pendahuluan}

Pemerolehan bahasa (language acquisition) terjadi pada pemerolehan bahasa pertama atau yang lebih dikenal dengan bahasa ibu yang mana dalam bahasa Inggris biasanya disebut dengan mother tongue, selanjutnya pemerolehan bahasa terjadi pada pemerolehan bahasa kedua, yaitu pemerolehan bahasa Inggris. Pemerolehan bahasa yang dikaji pada penelitian ini adalah pemerolehan bahasa Inggris pada anak yang diperoleh melalui media sosial berbasis video, yaitu YouTube yang dengan mudah dapat diakses dimana saja, kapan saja, dan oleh siapa saja, termasuk dapat diakses dengan mudah oleh anak-anak. Anak-anak dapat menyaksikan beragam video atau tontonan berbasis bahasa asing dari seluruh dunia dengan mudah melalui YouTube. YouTube memuat video-video menarik yang tidak hanya menampilkan tontonan anakanak, karena sifatnya umum untuk semua usia. Pengawasan dan lock system video harus dilakukan orang tua agar anak-anak mendapatkan tontonan yang layak dan bernilai edukatif, hal ini dilakukan sebagai upaya untuk melindungi anak-anak dari tontonan-tontonan yang tidak sesuai dengan usia anak tersebut dalam sosial media. Hal ini sebagaimana dinyatakan oleh Kurniati (2020:30) bahwa pengaruh media sosial berimbas tidak hanya bagi orang dewasa, juga bagi anak-anak. Apabila penggunaan berlebihan, pengaruh negatif mungkin saja merambah pada diri anak-anak. Pengaruh positifnya, sering kali dapat ditemukan pada anak-anak yang cenderung cerdas. Pada Anak yang cenderung cerdas kegiatan menonton video pada media 
sosial YouTube secara terus menerus membuatnya ingin juga mencoba atau menirukan hal yang ditontonnya, seperti dengan menirukan bahasa atau kegiatan eksperimen.

Anak-anak dapat dijadikan sebagai subjek penelitian karena kepolosan dan selalu menyikapi sesuatu dengan alami (natural). Penelitian dengan subjek anak-anak nyatanya lebih menyenangkan dan menantang. Hal ini karena untuk mendapatkan data atau informasi, penelitian harus berjalan santai dan tidak terburu-burudengan mengikuti alur atau ritme anak-anak. Subjek dalam penelitian ini merupakan seorang anak yang terlahir di zaman milenial, dimana sejak ia lahir telah melihat dan disuguhkan berbagai teknologi komunikasi. Jika ditinjau dari sisi urutan pemerolehan bahasanya, pemerolehan bahasa kedua diperoleh setelah anak mempelajari atau mendapatkan bahasa ibu. Tidak seperti di Negara asia lainnya yang menggunakan bahasa nasional sebagai bahasa pertama, bahasa Indonesia merupakan bahasa kedua karena banyak anak Indonesia yang memiliki bahasa pertama, yaitu bahasa ibu yang berupa bahasa daerah, tetapi bahasa kedua lazimnya digunakan sebagai pembelajaran bahasa asing. Pada penelitian ini, bahasa kedua yang digunakan adalah bahasa asing, yaitu bahasa Inggris.

Adapun Penelitian terkait mengenai pemerolehan bahasa pada anak usia di bawah lima tahun (balita) pernah dilakukan oleh Nurjamiaty (2015, 42-62) dengan penelitiannya yang berjudul "Pemerolehan Bahasa Anak Usia Tiga Tahun Berdasarkan Tontonan Kesukaannya Ditinjau dari Kontruksi Semantik". Penelitian tersebut menghasilkan proses pemerolehan bahasa yang terjadi pada anak usia tiga tahun dengan tontonan kesukaannya, kartun Boboboy, selanjutnya anak yang diteliti meniru tuturan yang terdapat dalam film kartun tersebut. Lalu, penelitian selanjutnya pernah dilakukan oleh Yulia Eka Salnita et. al (2019, 137-145) dengan penelitiannya yang berjudul "Pemerolehan Bahasa pada Anak Usia 3 Tahun". Penelitian tersebut menghasilkan tataran fonologi, sintaksis, dan tataran semantik pada anak usia 3 tahun. Terdapatperbedaan antara penelitian yang telah dilakukan dengan penelitian ini, yaitu media yang digunakan. Penelitian ini lebih mengedepankan pemanfaatan teknologi internet, mengingat saat ini manusia tidak lepas dari penggunaan IT (Information Technology). Penelitian menggunakan media YouTube tidak lagi menggunakan media televisi. Hal ini dikarenakan media YouTube dinilai telah banyak digunakan oleh kalangan anak-anak karena di dalamnya terdapat video-videoyang dapat dimanfaatkan sebagai pembelajaran anak.

Psikolingistik merupakan gabungan dari dua ilmu, yaitu psikologi dan linguistik. Ilmu psikolinguistik yang menggabungkan dua ilmu yang berlainan ini, keduanya sama-sama mengarah atau bermuara pada bahasa. Bahasa dan pikiran menjadi dua studi yang fokus dibicarakan pada bidang ini. Psikolinguistik mempelajari faktor-faktor psikologis dan neurobiologis yang memungkinkan manusia memperoleh, menggunakan, dan memahami bahasa.

Dardjowidjojo (2018:7) mengungkapkan bahwa psikolinguistik mempelajari empat topik utama, yaitu komprehensi, produksi, landasan biologis dan neurologis, serta pemerolehan bahasa . Brown (2007: 1) menyatakan bahwa mempelajari bahasa kedua adalah pekerjaan yang membutuhkan waktu lama dan rumit. Ini dikarenakan pikiran dan seluruh diri anda terpengaruh saat berusaha melalui batasan-batasan bahasa pertama dan berusaha memperoleh bahasa baru, budaya baru, dan cara baru dalam berpikir, merasakan, dan bertindak. Hal ini tentu memiliki tantangan tersendiri karena ketika seseorang mempelajari bahasa di luar bahasa ibu maka mereka harus beradaptasi dengan budaya bahasa tersebut.

Pemerolehan sebuah bahasa tidak dengan begitu saja dapat dimiliki dari lahir. Terdapat sebuah proses dan tahapan dalam pemerolehan sebuah bahasa. Ada dua faktor dalam proses pemerolehan bahasa pada anak. Pertama adalah faktor alamiah, dimana menurut Hendriyanto dan Putri (2014: 3) bahasa akan dapat terjadi jika perbuatan sering dilakukan oleh manusia secara berulang-ulang (continuously) akibatnya, ingatan/memori manusia akan menyimpan tanda, simbol, dan lambang yang pada akhirnya akan membentuk bahasa verbal dan nonverbal yang digunakan sebagai alat komunikasi antar manusia. Pernyataan ini sama dengan pandangan kaum strukturalisme yang mengatakan bahwa bahasa itu diperoleh karena adanya faktor latihan yang terus menerus. Dalam hal ini, kaum strukturalisme tersebut berlandaskan pada psikologi behaviorisme. B.F Skinner adalah tokoh behaviorisme. Psikologi behaviorisme ini berpandangan bahwa segala sesuatu yang dilakukan dapat terjadi karena adanya faktor kebiasaan atau latihan. Faktor yang kedua adalah lingkungan, dimana proses pemerolehan bahawa anak diawali dari kemampuan mendengar kemudian meniru suara yang didengarnya yaitu dari lingkungan tempat ia tinggal dan dibesarkan. Dalam pemerolehan bahasa anak, lingkungan memberikan stimulus dan model pada anak. Dengan demikian, kualitas lingkungan bahasa teramat penting bagi seorang pembelajar bahasa untuk berhasil mempelajari bahasa baru atau bahasa kedua. Oleh karena itu, konsep dasar pada penelitian ini merujuk pada teori behaviorisme dimana bahasa kedua akan dapat diperoleh dan dikuasi karena faktor 
kebiasaan. Seorang anak dapat menguasai bahasa kedua bila dia semakin sering mendapatkan stimulus dari luar yang membuatnya senang untuk menggunakan bahasa kedua.

Setiap orang yang telah memiliki bahasa pertama memungkinkan untuk memiliki bahasa kedua. Merujuk pada Hendriyanto dan Putri (2014:12) bahasa kedua ialah bahasa yang dimiliki seseorang sesudah menguasai bahasa pertama dan bahasa tersebut digunakan sebagai alat komunikasi berdampingan dengan bahasa pertama. Oleh karena itu, bahasa kedua biasanya diperoleh dalam lingkungan sosial tempat bahasa tersebut berada. Sedangkan menurut Musfiroh (2017:97) mempelajari bahasa kedua didefinisikan sebagai cara seseorang untuk mempelajari sebuah bahasa selain bahasa ibu, baik di dalam maupun di luar ruangan, serta formal maupun informal.

Banyaknya media sosial saat ini dimanfaatkan banyak kalangan, baik itu orang tua maupun anakanak untuk proses pembelajaran. Salah satu media sosial tersebut adalah YouTube, media sosial ini merupakan social media-based video yang sangat sering diakses. Beberapa konten dapat ditemukan di dalam media sosial YouTube, seperti video pembelajaran, tutorial membuat sesuatu, review produk, dan lain-lain. YouTube adalah situs yang dapat digunakan seseorang untuk mencari informasi berupa video, yang di dalamnya terdapat audio dan visual. Berselancar di YouTube tidak hanya untuk mencari video yang diinginkan, situs YouTube dapat pula digunakan untuk mengunggah dan membagikan video yang dimiliki ke jagat raya dunia (Muhaemin, 2017: putra, 2018). Bagi anak-anak sendiri terdapat media sosial YouTube Kids yang dijadikan sebagai tontonan, hiburan dan juga sarana edukasi pembelajaran bahasa. Anak-anak dengan cepat dan mudahnya meresapi dan meniru apa yang ia lihat dan dengar dari media YouTube.

Berdasarkan latar belakang tersebut, identifikasi masalah penelitian ini: kosakata bahasa Inggris apa saja yang didapatkan anak usia 5 tahun dari video pada media sosial YouTube? Tujuan penelitian ini adalah untuk mendeskripsikan dan menganalisis kosakata bahasa Inggris yang didapatkan anak usia 5 tahun melalui media sosial YouTube.

\section{Metode}

Jenis penelitian ini adalah deskriptif kualitatif, yaitu melakukan analisis hanya sampai deskripsi, serta menganalisis dan menyajikan fakta secara sistematik sehingga dapat lebih mudah dipahami dan disimpulkan. Teknik pengumpulan data pada penelitian ini adalah wawancara, yaitu berupa percakapan antara penutur dan lawan tutur dimana peneliti akan memberikan beberapa pertanyaan tentang kosakata yang didapatkan melalui YouTube oleh anak usia 5 tahun yang dibutuhkan pendekatan mendalam agar memperoleh hasil penelitian yang valid. Oleh karena itu, Peneliti dalam hal ini adalah penulis sangat berperan sebagai instrumen kunci karena perlu mempertimbangkan berbagai aspek di antaranya adalah daya simak dan daya ingat mengenai kejadian yang dilakukan saat melakukan penelitian. Penelitian ini meneliti pengaruh kebiasaan seorang anak yang telah menonton tontonan berbahasa Inggris sejak usia 5 tahun. Subjek penelitian ini adalah seorang anak perempuan berusia lima tahun bernama Ashimah Samha Dalisha. Kebiasaan tersebut menimbulkan pengaruh terhadap pemerolehan bahasa kedua yang dilakukan karena adanya proses pengulangan secara terus menerus atau berkelanjutan. Peneliti akan memaparkan bagaimana subjek menunjukkan bentuk pengaruh yang ia dapatkan dari pemerolehan bahasa melalui media social YouTube. Analisis penuturan dilakukan terhadap anak tersebut, yaitu pada saat subjek bermain atau berbincang dengan keluarga. Anak yang diteliti sangat responsif saat menjawab beberapa pertanyaan yang disampaikan untuk memenuhi penelitian ini. Penelitian ini didukung oleh rekaman dan kemudian ditranskrip menjadi sebuah data yang dicantumkan sebagaimana tertulis dalam penelitian ini. Perekaman yang dilakukan hanya menggunakan perekam audio dan strategi peneliti saat meneliti anak ini adalah merekamnya diam-diam tanpa diketahui oleh anak yang diteliti. Selanjutnya data hasil rekaman tersebut ditranskrip ke dalam bentuk tulisan. Pengujian keabsahan data ini dilakukan teknik kredibilitas. Langkah kredibilitas ini ditempuh hanya dengan langkah triangulasi. Triangulasi data dilakukan dengan cara mengambil data dari berbagai suasana, waktu dan tempat. Triangulasi situasional dilakukan dengan cara mengamati subjek dalam berbagai situasi, dan triangulasi metode pengumpulan data yaitu menggunakan beberapa alat atau instrumen agar data yang terkumpul lebih akurat.

\section{Hasil dan Diskusi}

Wawancara dilakukan dengan memberikan beberapa pertanyaan terkait pemerolehan kosakata bahasa Inggris yang didapatkan anak pada tataran kata benda, kata sifat, kata kerja, frasa, dan kalimat sederhana. Uraian mengenai pemerolehan kosakata tersebut dapat terlihat pada tabel dan dijelaskan dalam 
uraian peristiwa tuturan. Pemahaman bahasa Inggris sebagai bahasa kedua yang diperoleh melalui pengaruh tontonan di YouTube didapatkan oleh subjek karena proses atau kegiatan menonton video pada YouTube dilakukan secara berulang-ulang, dimana subjek dapat menonton tayangan yang sama lebih dari satu kali dalam sehari.

Tabel 1. Pemerolehan Kosakata

\begin{tabular}{clllll}
\hline No. & Kata Benda & \multicolumn{1}{c}{ Kata Kerja } & Kata Sifat & \multicolumn{1}{c}{ Frasa } & Kalimat \\
\hline 1 & Frozen & Glow & Big & Big ball & It is raining \\
2 & Daddy & Conceal & Beautiful & Blue Dress & I am watching \\
3 & Brother & Keep & White & The wind & \\
4 & Snowman & Do & Blue & Foot print & \\
5 & Door & Feel & & Good girl & \\
6 & Chair & & Is howling & \\
7 & Ball & & Don't feel & \\
8 & Flower & & To be seen & \\
9 & Snow & & & \\
10 & Strom & & & \\
11 & Mountain & & & \\
12 & Dress & & & \\
\hline
\end{tabular}

\section{Peristiwa Tuturan 1}

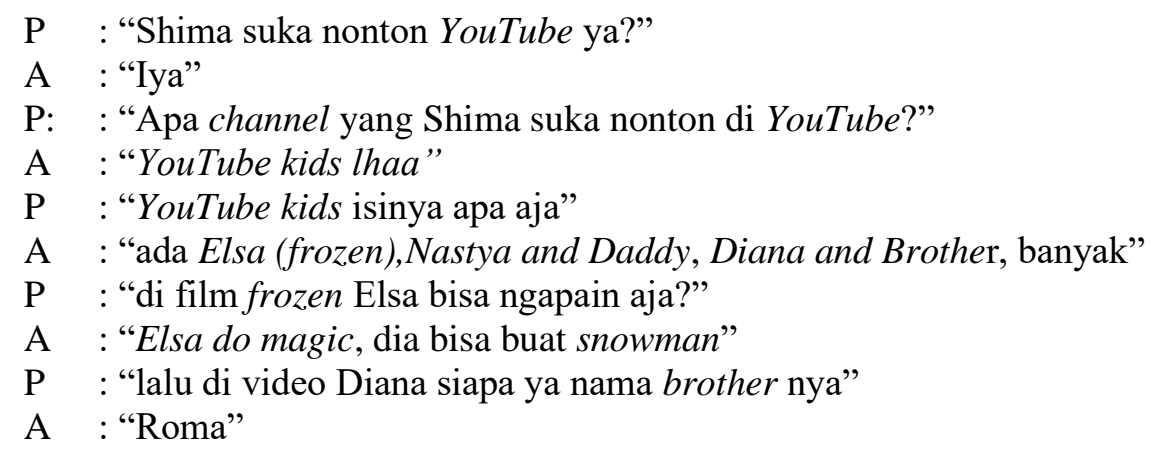

Hasil wawancara peneliti dengan subjek penelitian dapat dilihat bahwa subjek menggunakan bahasa Indonesia sebagai bahasa ibu (B1) dengan mengombinasikan bahasa Inggris sebagai bahasa kedua (B2). Pertanyaan yang diajukan peneliti menggunakan bahasa ibu dari sang subjek, Ashimah dapat memahami pertanyaan dengan baik dan menjawab pertanyaan dengan selaras.

Pada potongan percakapan di atas dapat dipahami bahwa tontonan yang paling digemari oleh Ashimah adalah YouTube dengan pengaturan video atau tontonan khusus anak-anak. Pengaturan khusus adalah bagian dari YouTube yang hanya berisikan tontonan anak-anak, seperti kartun, lagu anak, dan vlog anak-anak dari berbagai Negara. tontonan serial di YouTube yang ditonton Ashimah menggunakan bahasa Inggris sebagai bahasa ibu (B1). Saat peneliti menanyakan content apa saja yang biasa Ashimah tonton, dengan fasih Ashimah menyebutkan pemeran-pemeran dari tayangan yang ditontonnya. Dilanjutkan dengan pertanyaan yang diajukan oleh peneliti, apakah ia mengingat dan memahami makna kata dari video yang ia saksikan dan subjek menjawab "do magic dan membuat snowman". Pada pertanyaan berikutnya pun, Ashimah dengan cepat menjawab bahwa brother (saudara laki-laki) Diana adalah "Roma". Jawaban yang diberikan oleh Ashimah dapat diketahui bahwa ia mengingat dan memahami makna kata yang muncul pada film frozen, walaupun bahasa yang digunakan dalam video tersebut adalah Bahasa Inggris. Jawaban Ashimah menunjukkan bahwa ia menggunakan bahasa Inggris sebagai bukti bahwa ia memperoleh pengetahuan mengenai bahasa Inggris dari video tersebut karena melakukannya secara berulang. Hal ini sesuai dengan teori behaviorisme yang diuraikan pada pendahuluan bahwa pemerolehan bahasa dapa terjadi karena kebiasaan atau latihan. 


\section{Peristiwa Tuturan 2}

P : "kenapa sih Shima suka nonton Elsa?"

A : "soalnya elsa beautiful, dress nya bagus-bagus"

$\mathrm{P}$ : "dress mana yang shima suka"

A :"blue dress, nanti bunda mau beliin"

$\mathrm{P} \quad$ : "katanya shima hafal lagu frozen yang let it go ya, nyanyiin dong?

A : "snow glows white on the mountain tolight not a footprint to be seen nannaaaa selation and the queen. The wind is howling like this swirling storm inside yuden keep it in heaven knows I tried. Don't let them in don't let them see be the good girl you always have to be. conceal don't feel don't let them knooowww. wey know they know. Let it go... let it goo can hold it back anymore."

Potongan percakapan di atas juga memperlihatkan penggunaan bahasa Inggris sebagai bahasa campuran sang anak. Ia menjawab pertanyaan peneliti dengan menjawab "elsa beautiful" yang dalam bahasa Indonesia memiliki arti 'karena elsa cantik'. Selain itu Ashimah juga bisa menjawab kenapa elsa cantik dengan mengatakan "dress" nya bagus-bagus. Jawaban dari Ashimah menunjukkan bahwa alasan ia gemar menonton video elsa/frozen adalah karena pemeran utama dalam film tersebut cantik dan memiliki gaun yang indah. Anak usia lima tahun sangat wajar jika menyukai hal-hal yang berhubungan dengan princess. Selain itu jawaban "blue dress" juga dapat menjadi bukti bahwa Ashimah menggunakan bahasa Inggris sebagai B2 sebagai pengaruh dari media sosial YouTube karena kata-kata "blue dress"adalah kata-kata tentang warna yang sering didengarnya.

Berikutnya yang dapat diketahui dari percakapan di atas adalah Ashimah bisa menyanyikan lagu yang ada di video/film frozen dengan baik. Perihal ini menunjukkan bahwa Ashimah tidak menonton video film frozen ini hanya sekali, melainkan berkali-kali hingga ia dapat menyanyikan lagu berbahasa Inggris ini dengan baik walaupun terdapat beberapa kesalahan dalam pelafalan serta lupa terhadap lirik yang ia nyanyikan, tetapi jika dinilai secara keseluruhan ia dapat menyanyikan dengan baik.

Kesalahan yang terjadi saat Ashimah menyanyikan lagu let it go dapat dilihat pada kutipan di atas yang telah digaris bawahi. Ashimah melafalkan 'tolight' yang seharusnya dilafalkan dengan kata 'tonight'. Kesalahan berikutnya Ashimah lupa lirik selanjutnya. Lirik 'nannaaaa selation and the queen' seharusnya ' a kingdom of isolation and it looks like I'm the queen'. Hal ini wajar saja terjadi karena lirik dinyanyikan dengan tempo yang cukup cepat. Kesalahan berikutnya adalah kesalahan lirik 'yuden' seharusnya 'couldn't'. salah lirik juga terdapat pada kata 'wey' seharusnya 'well'.

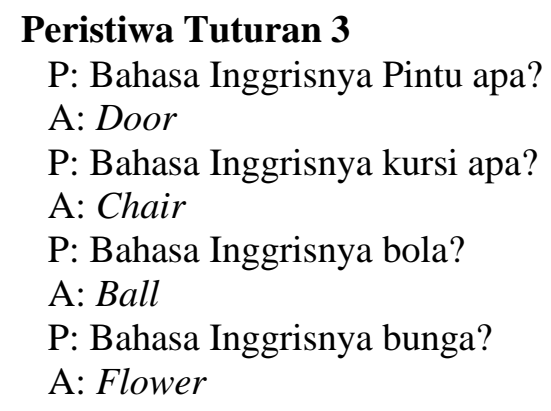

Peneliti melanjutkan dengan memberikan pertanyaan dengan tujuan untuk mendeskripsikan sejauh mana sang anak mendeskripsikan tentang B2 yang ia gunakan. Pertanyaan yang diberikan oleh peneliti seputar tentang benda-benda umum yang berada disekitarnya. Pertanyaan pertama peneliti menanyakan arti kata 'pintu' dalam bahasa Inggris. Ashimah dapat menjawabnya dengan tepat, ia menjawab 'door' dengan pengucapan yang fasih. Kata 'door' dalam bahasa Inggris memiliki deskripsi 'a flat objet that is used to close the entrance of something such as a room or building or the entrance itself' sebagai arti meja dalam bahasa Inggris.

Pertanyaan kedua peneliti memberikan pertanyaan arti kata'kursi'dalam bahasa Inggris. Ashimah dapat menjawabnya dengan tepat, ia menjawab 'Chair' dengan fasih, kata 'chair' memiliki deskripsi ' $a$ warehouse has function for sit down'. Begitu pula dengan pertanyaan ketiga, peneliti masih memberikan pertanyaan seputar benda-benda umum yang ada di sekitarnya. Peneliti memberikan pertanyaan arti kata 'bola' dalam bahasa Inggris. Ashimah dapat menjawabnya dengan tepat, ia menjawab 'ball' dengan fasih, 
kata 'ball' dalam bahasa Inggris memiliki deskripsi 'any object in the shape of sphere especially one used as a toy by children or in various sports such as tennis and football' sebagai arti bola dalam bahasa Inggris. Pertanyaan terakhir penelitian memberikan pertanyaan arti kata 'bunga'. Ashimah dapat menjawabnya dengan fasih, ia menjawab 'flower', kata 'flower' memiliki deskripsi 'the part of a plant that is of the brightly colored and has a pleasant smell'.

\section{Peristiwa Tuturan 4}

P: "Asimah tau ga bahasa inggrisnya bola besar?" (saat wawancara ia sedang memegang bola)

A: big ball

P: "kalau bunga yang cantik?"

A: "beautiful flower"

Peneliti sengaja memberikan pertanyaan di atas untuk mendeskripsikan tingkatan kelas kata yang diperoleh subjek dari menonton video YouTube. Saat ditanyakan bahasa Inggris dari frase 'bola besar' dan 'bunga cantik', Ashimah dengan tepat menjawab 'big ball' dan 'beautiful flower'. Hal ini menunjukkan bahwa Ashimah sudah bisa membuat Noun Phrase.

\section{Peristiwa Tuturan 5}

P: "Di luar sedang hujan tuh, Bahasa Inggrisnya apa ya?"

A: "It's raining mami"

$\mathrm{P}$ : "What are you doing right now?"

A: "I'm watching Elena of avalor"

Pada potongan percakapan di atas peneliti mencoba memberikan pertanyaan sesuai dengan keadaan yang sedang berlangsung pada saat itu. Pertanyaan pertama diajukan dengan menggunakan bahasa Indonesia, Ashimah menjawab dengan lancar dan dengan tenses yang tepat menggunakan bahasa Inggris. Ia menjawab it's raining mami yang berarti sedang hujan mama. Pada pertanyaan kedua Ashimah mampu memahami pertanyaan dalam bentuk bahasa Inggris dan menjawabnya dengan tepat. Saat Ashimah menjawab 'I'm Watching Elena of Avalor' sesuai dengan yang sedang dia saksikan pada saat itu.

\section{Simpulan}

Berdasarkan wawancara yang telah dilakukan oleh peneliti, dapat diketahui bahwa subjek penelitian mendapatkan pemerolehan bahasa kedua melalui pengaruh media sosial YouTube. Melalui media sosial ini, subjek memperoleh banyak kosakata dan memiliki kemampuan untuk berdialog dengan cukup baik menggunakan bahasa Inggris. Hasil kosakata yang diucapkan subjek pada penelitian ini adalah 12 kata benda, 5 kata kerja, 4 kata sifat, 8 frasa, dan 2 kalimat sederhana. Kemampuan berbahasa Inggris dari subjek dapat terlihat dari pemahamannya mengenai tontonan yang ia saksikan, ia dapat mendeskripsikan bahwa film yang ia saksikan adalah film yang menceritakan tentang seorang putri cantik yang memiliki kekuatan salju. Selain itu pemahamannya juga dapat terlihat pada kemampuan subjek menyebutkan benda-benda di sekelilingnya serta mampu membuat frasa dan kalimat dalam bahasa Inggris. Melalui video musik, subjek juga mendapatkan kemampuan bernyanyi dengan menggunakan bahasa kedua. Meskipun beberapa kali subjek lupa terhadap lirik dan pengucapannya masih belum fasih. Kemampuan ini ia dapatkan karena adanya pengulangan atau kebiasaan. Ia menonton sebuah video secara berulang-ulang dan terus menerus sehingga menimbulkan pemahaman, kebiasaan dan terjadi pengaplikasian. Media sosial berbasis video yang marak digunakan saat ini, yaitu YouTube sangat mempengaruhi pemerolehan bahasa Inggris yang diteliti pada penelitian ini. Dalam aplikasi YouTube banyak terdapat video pembelajaran untuk anak-anak yang menggunakan bahasa Inggris, sehingga dengan mudah orang tua menyuguhkan anaknya untuk belajar. YouTube memiliki peran penting dalam pemerolehan bahasa anak. Pemerolehan dan Pembelajaran bahasa anak dapat dipelajari melalui media YouTube, dimana visual dan audio pada YouTube menarik dan memudahkan anak memperoleh bahasa dan mengingat bahasa dengan baik. Dalam penelitian ini, YouTube sangat berperan untuk pengetahuan mengenai nomina warna dan numeralia pokok pada anak yang diteliti. Selanjutnya, untuk calon peneliti yang tertarik dalam melakukan penelitian mengenai pemerolehan bahasa Inggris anak, diharapkan dapat melakukan penelitian lanjutan dengan 
variabel yang lain yang belum diteliti selain pemerolehan kosakata pada tataran kata benda, kata sifat, kata kerja, frasa, dan kalimat sederhana. Selanjutnya, calon peneliti lainnya juga diharapkan dapat melakukan penelitian lanjutan dengan menggunakan objek penelitian yang berbeda agar mendapatkan hasil yang lebih baik lagi.

\section{Ucapan Terima Kasih}

Pada bagian ini, penulis ingin mengucapkan terima kasih kepada Allah Swt. yang telah memberi kesehatan dan berbagai kesempatan yang diperoleh. Suami dan anak-anak yang senantiasa memberikan dukungan dan pengertian yang tiada batas. Juga kepada Jurnal Hortatori yang telah memuat artikel ini.

\section{Daftar Rujukan}

Brown, H. Douglas. Principles of Language Learning and Teaching.America: Pearson Education, 2007. Print.

Dardjowijoyo, Soenjono. Psikolingistik: Pengantar Pemahaman Bahasa Manusia. Jakarta: Yayasan Pustaka Obor Manusia, 2014. Print.

Fardischa, Adinda. "Pengaruh Tontonan Berbahasa Inggris Dalam Media Sosial YouTube Pada Pemerolehan Bahasa Kedua Anak Umur Tujuh Tahun." Jurnal Pena Indonesia 6.1 (2020): 51-61. Doc Player. Web. April 2020.

Hendriyanto, Agus dan Nimas Permata Putri. Teori Belajar dan Pembelajaran Nahasa. Surakarta: Cakrawala Media, 2014. Print.

Imani, Rakaiza. "Pengaruh YouTube Terhadap Pemerolehan Bahasa Kedua Pada Anak Usia 8 Tahun."Jurnal Metabahasa 3.1 (2020): 11-24. Google Scholar. Web. 30 Januari 2020.

Muhammad. Metode Penelitian Bahasa. Jogjakarta: Ar-Ruzz Media, 2016. Print.

Musrifoh, Takdirotun. Psikolinguistik Edukasional: Psikolinguistik Untuk Pendidikan Bahasa. Yogyakarta: Tiara Wacana, 2017. Print.

Putra, Asaas, and Diah Ayu Patmaningrum. "Pengaruh YouTube di SmartPhone terhadap Perkembangan Komunikasi Interpersonal Anak." Jurnal Pendidikan Komunikasi 21.2 (2018): 159-172. Research Gate. Web. Desember 2018.

Rahardjo, Mudjia. Pengantar Penelitian Bahasa. Malang: Cendekia Paramulya, 2002. Print.

Sudarwati, Emy. dkk. Pengantar Psikolinguistik. Malang: Universitas Brawijaya, 2017. Print.

Sundari, Weli. "Pemerolehan Bahasa."Jurnal Warna 2.1 (2018) : 54-75. Google Scholar. Web. 1 Juni 2018.

Suroso, Eko. Psikolinguistik. Yogyakarta: Ombak, 2014. Print.

Suryabrata, S. Metodelogi Penelitian Deskriptif. Jakarta: Raja Grafindo Persada, 2012. Print. 